recently invented by $M$. Hamy which contains no internal electrodes. It is stated that the spectrum from this is identical with that from the Michelson cadmium lamp, which in the past has been used for experiments on the use of a wave-length of light as a fundamental unit of length. The comparison of a 6-in. and a 36-in. Fabry-Perot étalon illustrated how, by stepping up, lengths of the order of a metre and over can be measured accurately in terms of the ultimate unit.

The apparatus for silvering the plates used in interferometry methods of measurement was shown. The glass plate forms the anode of a vacuum vessel, and the cathode, of silver, is hung above it. The silver film is deposited on to the plate by the passage of an electric discharge. Films from I to 2 millionths of an inch in thickness can be obtained by this method.

In the workshop was a machine for facilitating the accurate lapping of pivots. In this the work in progress is magnified by projection, and the operator can compare the magnified image with an outline drawing, on the same scale, of the required profile.

The Physics Department was responsible for a large number of exhibits. Among them was an apparatus for the determination of the effect of humidity on the mobility of ions. A heated platinum wire mounted in an insulated metal tube is used for the production of the ions, which are drawn to the outer tube by the application of an electric field, the thermionic current being measured in the usual manner by means of an electrometer. The experiments are conducted at atmospheric pressure, and the humidity of the air surrounding the heated filaments can be adjusted. Another interesting exhibit was an apparatus for the determination of the heat loss from bare pipes. A graphite rod extending from end to end of a long iron pipe is heated electrically and the energy dissipated in it is measured. The corresponding temperatures at various points along the pipe are measured by thermocouples.

In the Sound Section was an apparatus for the photographing of sound waves. The passage of an electric spark across a short gap produces a single spherical sound pulse, the shadow of which is afterwards photographed under the illumination of a second spark. By using this apparatus in conjunction with sectional models of buildings, the acoustic properties of the latter can be determined.

The purity of the sounds produced by electrical apparatus used in acoustical work depends upon the wave-form of the electrical oscillations. A cathode ray oscillograph for the study of the latter was shown, the spot describing a circle on the fluorescent screen when the oscillations are sinusoidal.

Among the exhibits of the Radiology Section were Laue photographs of diamonds used as pivot bearings. In this connexion it has been found that the direction of the cleavage plane of the diamond with reference to the bearing surface is of great importance.

In the Optics Section were shown a flicker photometer for heterochromatic photometry and a spectrophotometric equipment using unpolarised light. I the latter, the absorbing optical parts are reduced to a minimum and measurements are made by a LummerBrodhun contrast field. As a result the instrument is very efficient at low illuminations. It possesses two collimators, and the light from the two sources is brought to approximate equality by means of rotating sector discs, the final balance being obtained by means of a wedge in the path of one of the beams.

In the Electrotechnics Department, Alternating Current Division, a recently constructed powermeasuring apparatus was on view, including a precision electrostatic wattmeter. Another exhibit consisted of the calibration of a 10,000 kilowatt 3-phase wattmeter operating at 6600 volts. This calibration is carried out by the employment of a fictitious load method in which the pressure and current coils are separately excited. In the Direct Current Division was shown a 5000 volt direct current set, for tests on equipment connected with railway electrification. In particular, it has been used for the testing of impregnated timber designed to protect railway workers from shock through accidental con tact with the live rail.

The exhibits of the Photometry Division included the apparatus for the standardisation of electric incandescent lamps in terms of the international candle and for the measurement of mean spherical candle power. In the experimental illumination building, demonstrations of the use of the daylightfactor meter-an instrument for the direct measurement of the proportions of the total external daylight reaching various points in a room-were in progress.

In the Wireless Division was an oscillograph used for analysing the wave-form of a valve oscillator and amplifier. A condenser in the grid circuit of an oscillator discharges linearly through a diode, and the discharge can be synchronised with the oscillations to be measured. The actual wave-form is traced out by the spot on the fluorescent screen of a cathode ray oscillograph. Another interesting feature was an apparatus for the measurement of the intensity of the field from a distant radio transmitting station.

A number of piezo-electric quartz resonators and oscillators for the purpose of radio frequency standardisation were shown in the Electrical Measurements and Standards Department. These oscillators form extremely constant sources of radio frequencies and are capable of controlling the output of valve generators. Another exhibit was a standard sonometer for the measurement of audio frequencies. The apparatus is very simple in principle. It consists of a phosphor-bronze wire loaded with a heavy weight. The wire passes between the poles of an electro-magnet and carries the current the frequency of which is under measurement. A sliding bridge with rack and pinion enables the free frequency of the wire to be brought into synchronism with that of the source. A pointer indicates the frequency directly. Various scales corresponding to modes of vibration in one, two, three, five, and ten loops, are used. The total range is from Ioo to ro, ooo cycles per second, with an accuracy throughout of $I$ in $I 000$.

\title{
Glacier Lassitude.
}

$\mathrm{O}^{\mathrm{N}}$ the Mount Everest Expedition, 1924, a peculiar condition of prostration and lassitude was experienced by its members whilst crossing ice under certain conditions. The appearance of this fatigue was found to coincide with the presence of a hot sun and a still air : this combination of conditions led to a saturation of the stratum of air on the glacier with moisture, so that the loss of heat from the body was interfered with. The effect was not due to altitude alone, since the lassitude disappeared the moment the observers left the glacier, and was not experienced in the early morning or late evening.

The explanation of this effect given by Major Hingston has been confirmed by some experiments undertaken by Leonard Hill and A. Campbell (Lancet, I925, vol. i. p. 939). The authors examined the 
effects of work with the bicycle ergometer in ordinary atmospheric air (2I per cent. oxygen) with a dry bulb temperature of $20^{\circ} \mathrm{C}$. and a low cooling power, and with a temperature of about $8^{\circ} \mathrm{C}$. and a high cooling power, and compared them with those produced by similar temperatures when the air breathed contained only II-I3 per cent. of oxygen: this level of oxygen was sufficiently low to produce symptoms of deficiency of oxygen in the experimental subject, such as weakness, giddiness, and cyanosis. It was found that an atmosphere with a low cooling power, or one with a lowered oxygen content, increased the pulse-rate more than one with a higher cooling power or a normal oxygen content: the effect of cooling power was observed whether the atmosphere contained a low or a normal amount of oxygen, while the effect of variation in the oxygen supply was seen independently of the cooling power of the atmosphere. When the two more disadvantageous conditions were combined in one experiment, that is, a lowered percentage of oxygen in the air breathed together with a low cooling power of this atmosphere, the increase in the pulserate was about equal to the increase due to the anoxæmia plus that due to the low cooling power. In the two subjects examined, the increase due to these two factors combined was about 24 and 36 beats per minute respectively: and at the same time the symptoms of anoxæmia and discomfort were more marked under warm conditions with a low oxygen tension. It was also found that there was no hindrance to the passage of oxygen across the pulmonary epithelium when air with a low oxygen tension but saturated with moisture was breathed, so that the results observed appear to be uue to the two factors of overheating of the body and of breathing oxygen at low tension. The pulse-rate alone is a guide to the distress of the beart under these conditions.

An obvious means of counteracting the effects of altitude is to increase the oxygen in the air breathed by a supply from some form of apparatus, but in the last expedition this method was found to be of little benefit. Hill and Campbell make the following suggestions to account for this finding. The observers have been in an atmosphere containing a low oxygen tension for a considerable time, and the effects of enriching this atmosphere with oxygen may be different from those observed in unacclimatised subjects submitted to acute anoxæmia for short periods. A further factor is the difficulty of, obtaining the full amount of oxygen given by the apparatus, some being almost inevitably wasted, without the wearing of a face-piece. Finally, the authors lay stress on the oxygen dissolved in the plasma in distinction from that in combination with the hrmoglobin in the corpuscles. It is of course the dissolved gas which is immediately available for the tissues, and the amount of this depends on the tension of the gas in the alveoli of the lung. Breathing air containing 30 per cent. oxygen at 29,000 feet would give only about $60 \mathrm{~mm}$. mercury tension of this gas in the alveolar air. Although this would saturate the hæmoglobin to 90 per cent., the amount of gas dissolved in the plasma would be only about two-thirds of that normally present when ordinary atmospheric air is breathed, so that the supply available for the tissues would still be distinctly subnormal.

\section{The Middle Carboniferous of the North of England.}

$\mathrm{M}$ R. W. S. BISAT'S paper on “ The Carboniferous Goniatites of the North of England and their Zones" (Proc. Yorks. Geol. Soc., N.S. vol. 20, I924, pp. 40-I24 and Pl. I.-X.) must take rank as one of the classics of Carboniferous stratigraphy. It provides the first clear guide to the "no man's land" of grits and shales which lie between the Carboniferous Limestone and the coal measures, while it will also be of the greatest value in the correlation of the Coal Measures themselves by providing a sure base from which to work.

The Goniatite succession is traced from the upper Viséan to the base of the Upper Coal Measures (of Lancs. and Yorks.). Zones $\mathrm{D}_{3}$ and $\mathrm{P}$ (the latter characterised by Goniatites s.s.) are retained in the Viséan. They are represented by the " knoll " limestones and the Bowland shales, which are regarded as in part contemporaneous. For the overlying beds, up to and including part of the Lower Coal Measures, the term Lancastrian is introduced. These beds are divided into the zones of Eumorphoceras (E), Homoceras $(\mathrm{H})$, Reticuloceras $(\mathrm{R})$ and Gastrioceras $(\mathrm{G})$ in ascending order. Hinde's Pendleside group (=Bowland shales) is found to be substantially equivalent to the Yoredales in age, and it is therefore proposed to discard the term, retaining Bowland shales as a facies name. The group belongs partly to $\mathrm{P}$ (Viséan) and partly to $E$ (Lancastrian). The Yoredales of Derbyshire belong mainly to a higher horizon (upper $\mathrm{E}$ and $\mathrm{H})$, corresponding to the Sabden shales of the Pendle area, while the overlying Kinderscout grit and shale is referred to $R$, leaving the upper portion of zone $R$ together with zone $\mathrm{G}$ for the higher grits and part of the Lower Coal Measures. The major (generic) zones named above are divided into minor (species) zones, of which twenty-one are recognised. Local details of the zonal determinations are given somewhat fully for south Yorkshire and Lancashire, with more brief reference to other areas.

The value of the stratigraphical portion of the paper is dependent on the full study of Goniatite palæontology on which it is based, and which forms the second (and larger) section. This constitutes a monograph on the family and one only regrets that it is not in more definitely monographic form. In its present relations, it is naturally concerned mainly with the diagnostic characters of species and varieties, and has less emphasis on their mutual relations and general evolution, though the section commences with an excellent key to the genera. The ontogenetic history is found to be strikingly uniform throughout the family, especially in regard to sutures, but with the usual independence in the rate of development of the several characters. Fifteen genera (four new) and fifty-six species (thirteen new) are described. The largest number belong to the zones $\mathrm{D}, \mathrm{P}, \mathrm{E}$, and $\mathrm{H}$, below the Kinderscout grit. Above that horizon only Reticuloceras (in the grits) and Gastrioceras (in the upper grits and Lower Coal Measures) appear to occur. A noteworthy feature is that the sutural development is at its maximum in the earliest zones, the species which follow being evidently katagenetic in this respect. The history of the other characters is less obvious, but the striking reduction in the number of species and the variability of the later forms seem to confirm a general decadence of the family. All those interested in Carboniferous stratigraphy will look forward with the highest interest to the further extension of Mr. Bisat's work.

The same part of the Yorkshire Geological Society's Proceedings contains a valuable résumé by Mr. G. W. Lamplugh of our present knowledge of the Speeton clays (the presidential address) as well as other important contributions.

NO. 2906, VOL. I I 6 ] 